\title{
The latest publications in the Grundtvig Society Series
}

(Roman numerals indicate serial number)

XXXII. Ole Vind, Grundtvigs historiefilosofi, Gyldendal, Copenhagen 1999, 645 pp. May be purchased through booksellers. DKK 300.00.

XXXIII. A.M. Allchin et al. (eds.), Grundtvig in International Perspective. Studies in the Creativity of Interaction, Aarhus University Press, Aarhus 2000, 209 pp. May be purchased through booksellers or direct from Aarhus University Press. DKK 248.00.

XXXIV. Anders Holm, Historie og efterklang: En studie i N.F.S. Grundtvigs tidsskrift Danne-Virke, Odense Universitetsforlag, Odense 2001, 139 pp. May be purchased through booksellers or direct from Odense Universitetsforlag. DKK 175.00 .

XXXV. Knud Eyvin Bugge, Grundtvig og slavesagen, Aarhus Universitetsforlag, Aarhus 2004, 226 pp. May be purchased through booksellers or direct from Aarhus Universitetsforlag. DKK 228.00.

XXXVI. Claus Bjørn, Grundtvig som politiker - Udgivet af Thorkild C. Lyby, Forlaget ANIS, Copenhagen 2007, 264 pp. May be purchased through booksellers or direct from Forlaget ANIS. DKK 295.00.

XXXVII. S.A.J. Bradley, N.F.S. Grundtvig: A Life Recalled. An Anthology of Biographical Source-Texts, Aarhus University Press, Aarhus 2007, 600 pp. May be purchased through booksellers or direct from Aarhus University Press. DKK 500.00 .

XXXVIII. Regner Birkelund, Frihed til falles bedste: En oppositionel stemme fra fortiden - om Grundtvigs frihedsbegreb, Aarhus University Press, Aarhus 2008, 685 pp. May be purchased through booksellers or direct from Aarhus University Press. DKK 448.00.

XXXIX. Anders Holm, To samtidige: Kierkegaards og Grundtvigs kritik af hinanden, Forlaget ANIS, Copenhagen 2009, 320 pp. May be purchased through booksellers or direct from Forlaget ANIS. DKK 299.00.

XL. Sune Auken and Christel Sunesen (eds.), Ved lejlighed: Grundtvig og genrerne, Forlaget Spring, Copenhagen 2014, 336 pp. May be purchased through booksellers or direct from Forlaget Spring. DKK 348.00.

XLI. Jette Holm, Helge Kjær Nielsen and Ruth Østerby (eds.), Nypagts-Bogen. Grundtvigs nytestamentlige oversattelser, Fønix, Copenhagen 2018. May be purchased through booksellers or direct from Forlaget Eksistensen. DKK 250.00 . 